\title{
An Analytical Approach for Junk Collecting Wireless Robot
}

\author{
Rahul Navghare $^{1}$, Mrunali Dhanorkar ${ }^{2}$, Vaishali Behaniya ${ }^{3}$ \\ Department of EXTC, Government College of Engineering, Nagpur ${ }^{1}$ \\ Department of EXTC, NIT Polytechnic, Nagpur ${ }^{2}$ \\ Department of Electrical Engineering, NIT, Nagpur ${ }^{3}$
}

\begin{abstract}
Our project mainly concentrates on mission clean India. one step toward swatch Bharat mission by our Anuourable prime minister which offering an easy,reliable solution to the common problem of inefficient garbage disposal faced within Public place. At present, which also implies that the main users of our product would be public place. For this, we have decided to implement a remote control, fully automated, junk bin. Here, the process includes the garbage collector moving through a series path, while stopping at each to collect garbage. This is the main process of the system. When the garbage container becomes full, a signal is generated and container continues straight to its dumpsite, without stopping at any other junction. The dumping of garbage is automated as well. This project mainly focuses on the importance of the product within the current world, with respect to places such as offices, production plants, hotels and especially schools, and how it really influences and enhances the quality of human life, by reducing the wastage of time and money.
\end{abstract}

Keywords: Garbage, Bluetooth, Lifting Maschine, Foot-path

\section{INTRODUCTION}

In modern times, the world has become a very busy place. This is mainly due to the rapid increase in population as well as physical resources. Along with these two factors, there is another factor which has, in turn, increased at an alarmingly high rate, which is the amount of garbage being disposed. As anyone would expect, this has become one of the major problems that not just our country, but the whole world, has come to face today. This dilemma is not limited to the towns and cities, but even in small villages, the collecting and disposing of garbage has become quite a headache for the community. With respect to human health and hygiene, as well as the cleanliness of the environment, the effectiveness of garbage disposal is very important.

Although the most common ways of disposing garbage are bins and bags, both these methods are implemented manually. This means that garbage disposal becomes a highly time-consuming and difficult process, and places such as schools, restaurants, hotels, offices, production plants are adversely affected. To overcome this possible catastrophe, an automated system, implemented with the use of electronics, introduced in such places, would prove to be highly efficient. It would get the job done easily, with minimal labour and hazards to health, as well as time and money being saved in the process. This idea was the base background for us to undertake this project. The thought of easing the task of collecting and disposing garbage was highly motivating, because we, as university students, are very much familiar with this unpleasant job. So that is where the foundation of our project was laid.

\section{SYSTEM ARCHITECTURE}

The importance of the product within the current world, with respect to public places, and how it really influences and enhances the quality of human life, by reducing the wastage of time and money. Due to people's busy life patterns, this has become unreliable. So, merged with the new technology, a proper garbage disposal system should be introduced for places where people gather frequently public places. The best way we can do this is to introduce an automated garbage disposal system. 


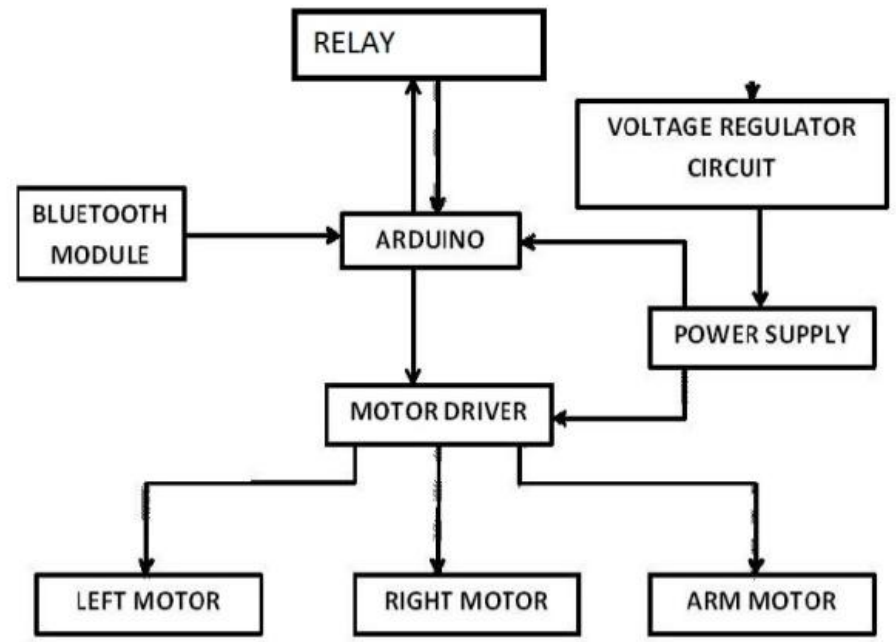

Fig. 1 Block Diagram

III. METHODOLOGY

The robot can travel in the predetermined path by using a combination of motors, drivers, and sensors connected to the aurdino. This system consists of four geared motors of 10rpm each, motor drivers and ultrasonic sensor. The ultrasonic sensors act as input to the aurdino. The motors are connected to the output of the aurdino through the drivers. The ultrasonic sensors detect the obstacles and the motors are made to rotate based on the pre-programmed instructions in aurdino The robot Garbage collection system consists of a set of a ARM connected to the motors. The mechanism will not operate for entirety of the vehicle operation and will rotate only for predetermined set of conditions. The main aim of the mechanism is to collect garbage which is of similar dimensions to that of juice cartons, crushed papers, and all light items whose height is between 5 to $10 \mathrm{cms}$. Mechanism is mounted on the front side of the base with an appropriate ground clearance. When the sensor detects an obstacle, the image processing is used to categorized the object as garbage or any living organism . The object detection is specifically used for safety of animals,so that they don't get harm . The garbage is pick and drop into a bin which is placed right behind the mechanism. The robot keeps collecting the garbage until it reaches certain height in the bin. Once the bin is filled the collected garbage is disposed to a selected place.

\section{STRUCTURE AND CONFIGURATION OF ROBOT}

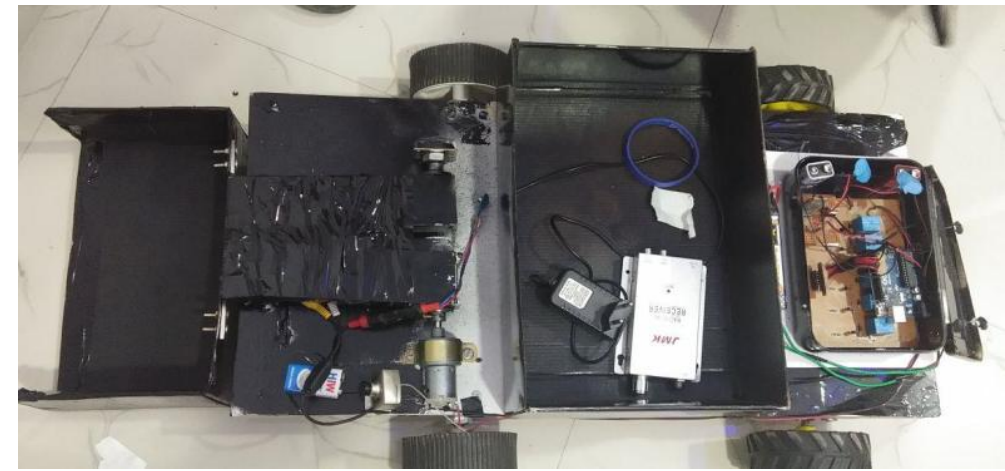

Fig. 2 Actual Implimentation

Some of the system requirements of the project are listed below:

$\times$ Motor driver circuit is used for the motion of the robot.

$\times$ Power supply as to get sufficient power for the motor.

$\times$ The robot requires a motion controlling unit i.e. Arduino Uno kit with adapter.

$\times$ Automatic motion of robot is obtained by using sensors in the navigation system.

$\times$ Metallic structure of the robot.

Other auxiliary circuits are added as per the requirements. 
Vol. 8, Issue 6, June 2019

Arduino Uno is the controller that coordinates the functionalities of the three stages to meet the real-time requirements. Arduino Uno is a microcontroller board based on the ATmega328. It has 14 digital input/output pins (of which 6 can be used as PWM outputs), 6 analog inputs, a $16 \mathrm{MHz}$ ceramic resonator, a USB connection, a power jack, an ICSP header, and a reset button. It contains everything needed to support the microcontroller; simply connect it to a computer with a USB cable or power it with an AC-to-DC adapter or battery to get started.

\section{CONCLUSION}

This project developed the robot for collecting the garbage in the college. Wireless communication (Bluetooth module) was applied to the robot for remote controlling. The developed can move at $0.5 \mathrm{~m} / \mathrm{s}$ on the ground surface. The robot can move with an average speed of $0.5 \mathrm{~m} / \mathrm{s}$ on the ground surface via wireless communication and collect large garbage. This robot is expected to overcome the garbage problem especially on the ground surface. However, this robot still be improved to operate automatically control from the more distance.

\section{REFERENCES}

[1]. Hesham Alsahafi, Majed Almaleky, "Design and Implementation of Metallic Waste Collection Robot", SEE2014 Zone I Conference, April 3-5, 2014, University of Bridgeport, Bridgpeort, CT, USA.

[2]. Saravana Kannan G, Sasi Kumar S, Ragavan R, Balakrishnan M,“Automatic Garbage Separation Robot Using Image Processing Technique”, International Journal of Scientific and Research Publications, Volume 6, Issue 4, April 2016

[3]. L. Wardhana, Belajar Sendiri Mikrokontroler AVR Seri ATMega8535, Yogyakarta: Andi Offset, 2006.

[4]. X. Gao and K. Kikuchi. Study on a Kind of Wall Cleaning Robot. Proc. The 2004 IEEE International Conference on Robotics and Biomimetics. 2004, pp. 391-394.

[5]. Song, M., Kim, B., Ryu, Y., Kim, Y., and Kim, S., "Control Robot System Using Android Smartphone”, The 7th International Conference on Ubiquitous Robots and Ambient Intelligence (URAI), Busan-Korea, 2010 